\title{
What regulatory guidance exists for multipurpose prevention technologies (MPTs)? A review of key guidance documents and their applicability to MPTs
}

Martha Brady

Population Council

Heeyoung Park

Follow this and additional works at: https://knowledgecommons.popcouncil.org/departments_sbsr-hiv

Part of the Health Policy Commons, Health Services Research Commons, Immune System Diseases Commons, International Public Health Commons, Medicine and Health Commons, Virus Diseases Commons, and the Women's Health Commons How does access to this work benefit you? Let us know!

\section{Recommended Citation}

Brady, Martha and Heeyoung Park. 2011. "What regulatory guidance exists for multipurpose prevention technologies (MPTs)? A review of key guidance documents and their applicability to MPTs." Washington, DC: Population Council. 


\section{(2) Population Council}

\section{What Regulatory Guidance Exists for Multipurpose Prevention Technologies (MPTs)? A Review of Key Guidance Documents and Their Applicability to MPTs}

By Martha Brady and Heeyoung Park

Building on its decades of support for developing contraceptives as well as products to prevent sexually transmitted infections (STIs), including HIV, the US Agency for International Development (USAID) is providing focused support to facilitate research and development, regulatory approval, and, ultimately, introduction of multipurpose prevention technologies (MPTs).

As part of this effort, the Population Council is spearheading work to clarify and inform regulatory pathways for MPTs. These are a unique and specialized subset of what regulatory authorities, including the US Food and Drug Administration (FDA), refer to as combination products. The FDA, 2I CFR 3.2(e), defines combination products as "a product comprised of two or more regulated components, any combination of a drug, device, and biological product, produced as a single entity."

Candidate products undergo review at the FDA depending on their designation, as follows:

- Drugs: Center for Drug Evaluation and Research (CDER)

- Biologics: Center for Biologics Evaluation and Research (CBER)

- Devices and Radioactive Therapy: Center for Devices and Radiological Health (CDRH)

Jurisdiction for review of combination products is determined by the Office of Combination Products (OCP) within the FDA, based on a given candidate's Primary Mode of Action (PMOA). The PMOA is the single mode of a combination product that provides the most important therapeutic action and is expected to make the greatest contribution to the overall intended effects of the product. The OCP is FDA-wide and makes its determinations about which sections of the agency to involve on a caseby-case basis depending on the specifics of the proposed product.' An important factor in the review of combination

'Guidance for Industry and FDA Staff:"How to write a request of designation (RFD)." www.fda.gov/Regulatorylnformation/ Guidances/ucm I 26053.htm. products is where the drug would fit within existing FDA structures. Some candidate multi-component drugs could be reviewed in one division of the FDA, while others may prompt review in two different divisions.

\section{Review of Existing Guidance}

The Population Council conducted a systematic review of key guidance documents to determine whether and how they might apply to MPTs for sexual and reproductive health (SRH). We developed a framework through which to review these documents, which included four key areas. We asked whether the guidance:

- Encompasses "combination products"

- Refers to both prevention and therapeutic products

- Considers multi-indication products

- Includes language and discussion of products for SRH

Searching through a broad range of guidance documents and guidelines from the FDA, European Medicines Agency (EMA), and International Conference on Harmonization of Technical Requirements for Registration of Pharmaceuticals for Human Use (ICH), we identified four documents which concern combination drug products, and thus might prove most relevant to MPTs. We reviewed the following documents, all of which are in the public domain and available online:

- FDA/CDER-Guidance for Industry: Co-development of Two or More Unmarketed Investigational Drugs for Use in Combination (draft Dec. 2010) ${ }^{2}$

- FDA/OCP-Guidance for Industry and FDA Staff: Early Development Considerations for Innovative Combination Products (Sept. 2006) ${ }^{3}$

\footnotetext{
${ }^{2}$ www.fda.gov/downloads/Drugs/GuidanceComplianceRegulatory Information/Guidances/UCM236669.pdf ${ }^{3}$ www.fda.gov/downloads/Regulatorylnformation/Guidances/ ucm I 26054.pdf
} 
- EMA-Guideline on Clinical Development of Fixed Combination Medicinal Products (Feb. 2009) ${ }^{4}$

- ICH-Guidance on Nonclinical Safety Studies for the Conduct of Human Clinical Trials and Marketing Authorization for Pharmaceuticals: M3R2 (June 2009) $)^{5}$

\section{Descriptions of Guidance Documents}

\section{Guidance for Industry: Co-development of Two or More Unmarketed Investigational Drugs for Use in Combination}

This guidance is intended to assist sponsors in the co-development of two or more novel (not previously marketed) drugs to be used in combination to treat a disease or condition. It provides recommendations and advice on how to address scientific and regulatory issues that will arise during co-development. The FDA issued this guidance because the existing developmental and regulatory paradigm focuses primarily on assessment of the effectiveness and safety of a single new investigational drug acting alone, or in combination with an approved drug. Because co-development will generally provide less information about the safety and effectiveness of the individual drugs, it will present greater risk compared to development of an individual drug. Therefore, the FDA believes that co-development should ordinarily be reserved for situations that meet the following criteria:

- The combination is intended to treat a serious disease or condition.

- There is a compelling biological rationale for use of the combination.

- A preclinical model or short-term clinical study on an established biomarker suggests that the combination has substantial activity and provides greater than additive activity or a more durable response compared to the individual agents alone.

- There is a compelling reason for why the agents cannot be developed individually.

The guidance is not intended to apply to development of fixed-dose combinations of already marketed drugs or to development of a single new investigational drug to be used in combination with an approved drug(s). It is also not intended to apply to vaccines, gene or cellular therapies, blood products, or medical devices.

\footnotetext{
${ }^{4}$ www.ema.europa.eu/docs/en_GB/document_library/Scientific_ guideline/2009/09/WC500003686.pdf

${ }^{5}$ www.ich.org/fileadmin/Public_Web_Site/ICH_Products/

Guidelines/Multidisciplinary/M3_R2/Step4/M3_R2_Guideline.pdf
}

\section{Guidance for Industry and FDA Staff: Early Development Considerations for Innovative Combination Products}

This document provides guidance to industry and FDA staff on developmental considerations for innovative products that combine devices, drugs, and/or biological products. It is intended to provide a context for initial discussions on the type of scientific and technical information that may be necessary for investigational or marketing applications for these combination products. As with other medical products, combination product development typically focuses on the scientific and technical issues raised by the particular product being developed. For a combination product, these scientific/technical issues will ordinarily reflect the combination product itself as well as its constituent parts. When combining products such as drugs or biologics and devices that are customarily developed using different regulatory paradigms, certain critical developmental issues, such as the interaction of the drug/biologic and device constituents, may not be readily apparent. Further, because of the breadth, innovation, and complexity of combination products, there is no single developmental paradigm appropriate for all combinations.

The FDA recommends that developers consider the scientific and technical issues raised by the combination product and its constituents, and propose an approach that appropriately addresses these issues without requiring duplicative or redundant studies. When the combination product is comprised of constituents that are chemically, physically, or otherwise combined or mixed and produced as a single entity, developers should consider and, as appropriate, evaluate the potential for a broad range of drug/biologic/ device interactions. For some combination products, the constituents may have synergistic effects that should be evaluated. In the context of these studies, it is appropriate to discuss approaches to avoid duplication/redundancy and to develop strategies to streamline the overlapping aspects of development.

\section{EMA Guideline on Clinical Development of Fixed Combination Medicinal Products}

This guideline provides guidance on the clinical strategy to be considered when developing fixed combination medicinal products containing two or more active substances, which can be either well-known or not yet authorized in the European Union for the intended claim. The development of fixed combination medicinal products will reflect the intended use (first- or second-line indication in patients inadequately controlled with individual 
component(s) of the combination) and the intended indication (treatment of one disease or, for example, two closely related diseases, such as hyperlipidemia and hypertension, or substitution indication). Combination packs would only be acceptable in exceptional cases, when there would be clear public health benefits for the treatment regimen and/ or compliance, taking into account the required justifications. Potential advantages and disadvantages of fixed combinations are also discussed.

\section{ICH Guidance on Nonclinical Safety Studies for the Conduct of Human Clinical Trials and Marketing Authorization for Pharmaceuticals}

A review of the $\mathrm{ICH}$ M3R2, section 17 provides additional guidance related to preclinical testing for combination products. Nonclinical toxicity testing is recommended for combinations. The scope of the nonclinical testing on individual components is determined by whether those components are used as single entities (complete testing required for all individual entities and the combination) or used in a fixed-dose combination and not individually (only combination testing required).

\section{Policy Analysis of Guidance: Application to MPTs for SRH}

Our analysis of the existing guidance documents suggests that while they are generally useful starting points for considering the issues raised by the potential of MPTs, none of them applies specifically to MPTs for SRH. Further, these documents focus on therapeutic and single-indication combination products, not on prevention products per se. Below we provide a brief policy analysis of each document, and summarize in Table I.

The draft FDA guidance on co-development, describing the criteria for determining when co-development is an appropriate option, makes recommendations about nonclinical and clinical development strategies, and addresses certain regulatory process issues. This guidance excludes fixed-dose combinations of already marketed drugs or development of a single new investigational drug to be used in combination with an approved drug(s). And while this guidance points out that "further new therapeutic approaches using combinations of drugs directed at multiple therapeutic targets is needed to improve treatment response or minimize development of resistance," prevention products and multi-indications are not mentioned in the document.

The OCP guidance describes general principles to consider when developing information to demonstrate the safety and effectiveness of a combination product and its constituent parts. In the drug constituent considerations (section V-B), this guidance explains that a new molecular entity (NME) is a critical consideration in the combination product. For example, "certain conventional pharmacology and toxicology studies may be necessary to establish the safety profile of the NME alone before beginning clinical investigation of the combination product." This guidance focuses on providing considerations and perspectives on scientific and technical issues in early development of innovative combination products, including drugs, biologics, and devices. It is quite general, and not specific to prevention drugs with multiple indications. This guidance makes no mention of prevention products and multi-indications.

The guideline from the EMA is for fixed-dose combination drug products, which define the combination of active substances within a single pharmaceutical form of administration. An example of fixed-dose combination drugs is multiple antiretrovirals (ARVs) combined into a single pill, which helps reduce pill burden. These guidelines mention prevention of disease for selecting doses of each substance, but the document focuses solely on therapeutics. While this guideline mentions multiple indications, it limits itself to treatment of one disease or two closely related diseases: "An indication must be a well-recognized disease state, or two closely related diseases, or a modification of a physiological or dysfunctional state, or a syndrome or pathological entity (section 6.I). The individual substances of a fixed combination may be intended to relieve simultaneously different symptoms of such a disease state."

\begin{tabular}{|c|c|c|c|c|}
\hline $\begin{array}{l}\text { Source of } \\
\text { guidance }\end{array}$ & $\begin{array}{l}\text { Includes information on } \\
\text { "combination products"? }\end{array}$ & $\begin{array}{l}\text { Refers to both therapeutic } \\
\text { and prevention products? }\end{array}$ & $\begin{array}{l}\text { Includes information on } \\
\text { multi-indication? }\end{array}$ & $\begin{array}{l}\text { RH issues } \\
\text { mentioned? }\end{array}$ \\
\hline I - CDER & YES & Therapeutic only & NO & $\mathrm{NO}$ \\
\hline $2-O C P$ & YES & Therapeutic only & NO & $\mathrm{NO}$ \\
\hline 3 - EMA & YES & $\begin{array}{l}\text { Both: however prevention is } \\
\text { only mentioned in } \\
\text { dosage proposal }\end{array}$ & $\begin{array}{l}\text { YES, but only for "two closely } \\
\text { related diseases such as hyperg- } \\
\text { lycemia \& hypertension...." }\end{array}$ & $\mathrm{NO}$ \\
\hline
\end{tabular}




\section{Distilling the Complexity around Number and Type of Indications}

Given the range and diversity of products, the types and number of ingredients and indications, and the various FDA designations required for review, we developed a framework to illustrate and distill this complexity. Table 2 provides a summary of selected products, indications, and their FDA designation. We have highlighted those which are already approved by the FDA, and are linked in some way to SRH (with exception of the combination vaccines). There are a number of multi-indication products in clinical trials that could potentially be developed as an MPT.

\section{Next Steps}

This review and analysis suggests several concrete next steps. First, we anticipate increased interaction with key regulatory agencies in the United States and abroad to help further clarify regulatory issues and challenges. Second, drawing upon knowledge and experience in the area of combination products, along with work around accelerated pathways, we will work with key individuals and institutions to develop a road map for regulatory pathways for MPTs. Finally, we hope this effort to understand and clarify regulatory processes will help the emerging field of MPTs.

\begin{tabular}{|c|c|c|c|c|}
\hline $\begin{array}{l}\text { Number of } \\
\text { ingredients }\end{array}$ & $\begin{array}{l}\text { Number of } \\
\text { indications }\end{array}$ & Product name & Indication(s) & $\begin{array}{l}\text { FDA } \\
\text { designation }\end{array}$ \\
\hline Single product & Single & Copper T IUD & Pregnancy prevention & CDER \\
\hline \multirow[t]{4}{*}{ Single product } & \multirow[t]{4}{*}{ Multiple } & Mirena $^{\circledR}$ IUS & Pregnancy prevention, $\mathrm{Rx}$ heavy bleeding & CDER \\
\hline & & Pitocin $^{\circledR}$ & $\begin{array}{l}\text { Induce uterine contraction; prevention of postpartum } \\
\text { hemorrhage }\end{array}$ & CDER \\
\hline & & Cytotec $^{\circledR}$ & Prevention of gastric ulcer; induce uterine contraction & CDER \\
\hline & & Condom & Pregnancy prevention, reduce STIs & $\mathrm{CDRH}$ \\
\hline \multirow[t]{5}{*}{ Multi-ingredient } & \multirow[t]{5}{*}{ Single } & Combined ARVs & HIV treatment; partial prevention of HIV & CDER \\
\hline & & Combined OCs & Pregnancy prevention & CDER \\
\hline & & Multi-valent vaccines & & \\
\hline & & $\mathrm{IPOL}^{\circledR}$ & Prevention of polio & CBER \\
\hline & & Flu vaccines & Prevention of influenza & CBER \\
\hline \multirow[t]{3}{*}{ Multi-ingredient } & \multirow[t]{3}{*}{ Multiple } & Multi-valent vaccines & & \\
\hline & & Prevnar $^{\circledR}$ & Prevention of invasive S. pneumoniae diseases & CBER \\
\hline & & Gardasil $^{\circledR} /$ Cervarix $^{\circledR}$ & $\begin{array}{l}\text { Prevention of HPV induced cervical, vulvar and rectal } \\
\text { cancers, and genital warts }\end{array}$ & CBER \\
\hline \multirow[t]{5}{*}{ Multi-product } & \multirow[t]{5}{*}{ Mutliple } & Combination vaccines & & \\
\hline & & DPT & Prevention of diphtheria, tetanus, and pertussis (DTP) & CBER \\
\hline & & MMR & Prevention of measles, mumps, and rubella & CBER \\
\hline & & PEDIARIX ${ }^{\circledR}$ & Prevention of polio, hepatitis B, and DTP & CBER \\
\hline & & Pentacel $^{\circledR}$ & $\begin{array}{l}\text { Prevention of polio, DTP, and invasive Haemophilus } \\
\text { influenzae type b disease }\end{array}$ & CBER \\
\hline
\end{tabular}

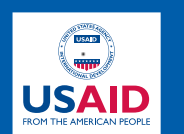

Population Council

This document was made possible through support provided by the United States Agency for International Development (USAID) under the terms of Cooperative Agreement No. AID-OAA-A-I0-00072. The contents are the responsibility of the authors and do not necessarily reflect the views of USAID or the United States Government.

The Population Council conducts research worldwide to improve policies, programs, and products in three areas: HIV and AIDS; poverty, gender, and youth; and reproductive health. Www.popcouncil.org

Suggested citation: Brady, Martha and Heeyoung Park. 20I I. “What regulatory guidance exists for multipurpose prevention technologies (MPTs)? A review of key guidance documents and their applicability to MPTs.” New York: Population Council.

Published in July 201 I. Copyright @20II Population Council.

This document may be reproduced in whole or in part without permission of the Population Council provided full source citation is given and the reproduction is not for commercial purposes. 